\title{
82. Calling Sub-programs (continued)
}

Often one program will need to pass information across to another - if so the main program will need to specify the data-names(s) where the data is to be placed -e.g.

\section{CALL 'CONVPERC' USING MATHS-MARK-OUT-OF-TEN, MATHS-PERCENTAGE.}

Where MATHS-MARK-OUT-OF-TEN already contains a mark which the subprogram is expected to convert to a percentage and MATHS-PERCENTAGE is a field where the sub-program can place the answer (Note - both of these fields will have been defined in the main program's Data Division in the normal way).

The sub-program will have a statement at the beginning of its Procedure Division stating how many data-items it expects to receive and what it will call them - e.g.

\section{PROCEDURE DIVISION USING SUBJECT-MARK-OUT-OF-TEN,} SUBJECT-PERCENTAGE.

(It is useful to use different names from the main program - as at different points in the program it might be useful to call the sub-program passing across - say - the English-mark or the French-mark).

Note that once the main program has called the sub-program in the example above, SUBJECT-MARK-OUT-OF-TEN, for example, becomes (temporarily) just another name for the area of memory called MATHS-MARK-OUT-OF-TEN by the main program. So if one program alters its contents, no copy of the original contents is kept by either program.

This is true until the sub-program finishes and transfers control back to the main program (using the EXIT PROGRAM command).

The sub-program will also require a Linkage Section in its Data Division where the size and type of these Data items is defined - e.g.

\section{LINKAGE SECTION.}

01 SUBJECT-MARK-OUT-OF-10 PIC 99.

01 SUBJECT-PERCENTAGE PIC 999.

Note these definitions must not conflict with the definition given to the related data-items in the main program.

If the sub-program needs any working locations these would be put in its Working-storage Section as normal.

Exercise

Complete the example program and sub-program. 